\title{
Immunohistochemical Localization of Betacellulin, a New Member of the EGF Family, in Normal Human Pancreas and Islet Tumor Cells
}

\author{
Jun-ICHIRo MIYAGAWA*, ToShIAKI HANAFUSA*, ReIKo SASADA**, KoJI YAMAMOTO*,***, \\ KoICHI IGARASHI**, KATSUMi YAMAMORI*, MASAHARU SENO\#, HIRoKo TADA*, \\ TaKao NAMMO*, Ming LI*, KazUya YAMAGATA*, Hiromu NAKAJIMA*, \\ MitsuYoshi NAMBA*, MASAMICHI KUWAJIMA\#\# AND YUJi MATSUZAWA* \\ * Department of Internal Medicine and Molecular Science, Graduate School of Medicine, Osaka University, 2-2 B5, \\ Yamadaoka, Suita, Osaka 565-0871, Japan \\ ** The Discovery Research Laboratory II, Discovery Research Division, Takeda Chemical Industries, Ltd., 10 Wadai, Tsukuba, \\ Ibaragi 300-4247, Japan \\ *** Department of General Medicine, Osaka University Hospital, 2-15 Yamadaoka, Suita, Osaka 565-0871, Japan \\ \# Department of Bioengineering Science, Faculty of Engineering, Okayama University, 3-1-1 Tsushima-Naka, Okayama 700- \\ 0082, Japan \\ \#\# Present address: Department of Laboratory Medicine, School of Medicine, Tokushima University, 3-18-15 Kuramoto-cho, \\ Tokushima 770-8503, Japan
}

\begin{abstract}
Betacellulin (BTC) purified from mouse $\beta$ cell tumor ( $\beta$ TC-3) is a new member of the epidermal growth factor (EGF) family which can bind receptor tyrosine kinase, EGF receptor (erbB1) and erbB4. It has been demonstrated that proBTC mRNA was abundantly expressed in human pancreas tissue, and that BTC converted amylase-secreting rat acinar cell line (AR42J) into insulin-secreting cells, suggesting that BTC might be important for the growth and/or differentiation of islet cells. However, the cell type producing BTC in the pancreas has not been clarified. In this study, we examined the localization of BTC in human pancreas and islet cell tumors. Immunohistochemistry using specific antibodies to human BTC revealed that this protein was produced in $\alpha$ cells and duct cells, and probably in $\beta$ cells in normal adult pancreas. Furthermore, strong immunoreactivity to BTC was detected in primitive duct cells of the fetal pancreas, and both insulinoma and glucagonoma cells also showed positive immunoreactivity to BTC. EGF receptor (erbB1) and erbB4 were expressed mainly in islet and duct cells, and duct cells, respectively. These results demonstrate the localization of BTC and its receptors, and suggest that BTC may be one of the factors that have physiologically important roles such as growth and differentiation of islet cells in the human pancreas.
\end{abstract}

Key words: Betacellulin, Growth factor, $\beta$-Cell, Differentiation, Pancreas

(Endocrine Journal 46: 755-764, 1999)

BETACELLULIN (BTC), a new member of the epidermal growth factor (EGF) family, has been

Received: March 25, 1999

Accepted: August 25, 1999

Correspondence to: Dr. Jun-ichiro MIYAGAWA, Department of Internal Medicine and Molecular Science, Graduate School of Medicine, Osaka University, 2-2 B5,Yamadaoka, Suita, Osaka 565-0871, Japan purified from the medium conditioned by a cell line of mouse $\beta$ cell tumor ( $\beta$ TC-3) [1]. Mature BTC is a 32-kilodalton glycoprotein and is thought to be processed by proteolytic cleavage from a precursor form (proBTC). The nucleotide sequence of human proBTC encodes a polypeptide consisting of 178 amino acid residues, and the carboxy terminal domain of BTC has $50 \%$ sequence homology with that of transforming growth factor- $\alpha$ (TGF- $\alpha)$. The 
proBTC gene was expressed in several mouse tissues including kidney and liver, suggesting that this growth factor might play a physiological role in normal tissues [2]. BTC has been shown to be a potent mitogen for rat vascular smooth muscle cells and retinal pigment epithelial cells in vitro [1]. This protein, like other members of the EGF family, has the ability to bind erbB1 (EGF receptor) and erbB4, and activates erbB receptor tyrosine kinase [3]. Shing et al. raised the possibility that BTC is primarily a ligand for another known member of the EGF receptor family such as erbB oncogene product because of the relatively low affinity of BTC to EGF receptor [1]. In fact, a novel receptor for BTC, erbB4, has been identified [4].

In the development of endocrine pancreas, islet cells arise from endodermal stem cells which lie in the primitive duct epithelium, and the islet structure is thought to be formed by budding from the pancreatic duct cells $[5,6]$. During the process of proliferation and differentiation of $\beta$ cells from islet precursor cells, many growth factors, cytokines and hormones are thought to act synergistically or coordinately. Some of these factors regulating the ontogeny of endocrine pancreas appear to be also important for the process of $\beta$ cell regeneration. Among the growth factors of the EGF family, TGF- $\alpha$ is expressed in human fetal pancreas, and its receptor, EGF receptor, is also expressed on these cells $[7,8]$. In transgenic studies, overexpression of TGF- $\alpha$ induced metaplastic changes in acinar cells into duct-like cells in the mouse pancreas [9-12], and coexpression of both TGF- $\alpha$ and gastrin transgenic genes in the pancreas significantly increased islet cell mass, indicating that TGF- $\alpha$ and gastrin could act synergistically to stimulate islet cell growth [13]. However, sequential and/or synergistic operation of other growth and differentiation factors also appear to be necessary for the physiological development of endocrine cell mass (islets) in the pancreas. Recently, it has been demonstrated that BTC transformed rat pancreatic acinar cell line, AR42J cells, into insulin-producing cells [14]. On the other hand, BTC has been shown to potentiate the growth of rat insulinoma cell line, INS-1 cells [15]. These evidence suggest that BTC is a good candidate for growth and/or differentiation factors for pancreatic endocrine cells. However, no information on the cell type(s) producing this growth factor in the pancreas has been available so far. As a first step to clarify the role of BTC in the growth and/or differentiation of pancreatic endocrine cells, we examined immunohistochemical localization of BTC protein in human fetal and adult pancreas, and islet cell tumor tissues.

\section{Materials and Methods}

\section{Materials}

Normal pancreas tissues were obtained from eight patients with gastric cancer $(\mathrm{N}=4)$, pancreatic cancer $(\mathrm{N}=3)$ and common bile duct cancer $(\mathrm{N}=1)$ at surgical operation. Fetal pancreas (about 16 weeks of gestation estimated from the fetal foot length) was obtained from legal abortion. Tissues of islet cell tumors were from six patients with insulinoma and two patients with MEN (multiple endocrine neoplasia) Type I with glucagonoma, and three patients with solitary glucagonoma. Before surgical operation, informed consent was obtained from all patients or families.

\section{Methods}

\section{Preparation of antibodies to human BTC}

A rabbit antiserum, pAb-MBT, was prepared against a synthetic oligopeptide, EGYIGARCERVDLFY. The sequence appears in the predicted carboxy-terminal-end region of the human BTC mature form (amino acid number 97-111) [2]. The oligopeptide was coupled to bovine thyroglobulin, emulsified in Freund's complete adjuvant, and injected subcutaneously into New Zealand white rabbits. Booster injections were given subcutaneously at 2-week intervals using the same quantity of antigen in incomplete Freund's adjuvant. Blood was collected 2 weeks after final injections and the serum was obtained. Another rabbit antiserum, pAb-CBT, against a synthetic oligopeptide, DITPINEDIEETNIA, a carboxy-terminal-end region of the predicted human BTC precursor molecule (amino acid number 164-178), was also prepared, as described above. This antibody is expected to recognize pro-BTC, but not the mature secreted form of BTC. Other growth factors of EGF family including EGF, TGF- $\alpha$, HBEGF (heparin-binding EGF-like growth factor) did not cross-react with these antibodies by immuno- 
blotting.

\section{Immunostaining for BTC}

Pancreas and islet cell tumor tissues were immediately fixed at the time of operation with $10 \%$ phosphate buffered neutral formalin for $5-8 \mathrm{~h}$ at $4^{\circ} \mathrm{C}$. After washing three times in $0.01 \mathrm{M}$ phosphate buffered saline (PBS), tissues were dehydrated with graded concentrations of ethanol series and embedded in paraffin. Paraffin sections (about $5 \mu \mathrm{m}$ thick) were deparaffinized with xylene, washed in PBS, and incubated with $3 \% \mathrm{H}_{2} \mathrm{O}_{2}$ solution for 30 min to block endogenous peroxidase. After washing in distilled water for $5 \mathrm{~min}$ and with $0.05 \mathrm{M}$ Tris- $\mathrm{HCl}$ buffer for $5 \mathrm{~min}$, sections were incubated with normal swine serum. Three-step immunoperoxidase method was performed using a rabbit anti-BTC antiserum diluted $1 / 200$ in Tris- $\mathrm{HCl}$ buffer containing $1 \%$ bovine serum albumin (BSA) for $30 \mathrm{~min}$, swine anti-rabbit immunoglobulins (DAKO, Glostrup, Denmark) diluted 1/200 in Tris- $\mathrm{HCl}$ buffer containing $1 \%$ BSA for $20 \mathrm{~min}$, and peroxidase-labeled, rabbit antiperoxidase immunoglobulins (PAP complexes) for 30 min. Positive reaction was visualized with 3amino-9-ethylcarbazol (AEC) (DAKO) in $0.1 \mathrm{M}$ acetate buffer ( $\mathrm{pH}$ 5.2) in the presence of $0.3 \% \mathrm{H}_{2}$ $\mathrm{O}_{2}$. For negative control, the primary antiserum was preabsorbed with excess amount of the peptide antigens, or replaced by pre-immune serum of the same animal. All procedures were performed at room temperature.

Immunostaining of pancreatic hormones (insulin, glucagon, somatostatin and pancreatic polypeptide), cytokeratin and erbB receptor families

For detection of pancreatic hormones and duct cell-specific cytokeratin, ABC (avidin-biotin complex) method was applied using $A B C$ kit (Vector Laboratories Inc., Burlingame, CA). Deparaffinized sections were treated with $0.3 \% \mathrm{H}_{2} \mathrm{O}_{2}$ in methanol, washed in PBS for $20 \mathrm{~min}$, and incubated with normal goat serum for $20 \mathrm{~min}$ at room temperature. Sections were then incubated with the following primary antibodies; guinea pig anti-porcine insulin antibody diluted $1 / 4000$ in PBS containing $1 \%$ BSA, rabbit anti-porcine glucagon antibody diluted $1 / 500$ in PBS containing 1\% BSA, rabbit anti-synthetic cyclic human somatostatin antibody diluted $1 / 2000$ in PBS containing 1\% BSA, rabbit anti-human pan- creatic polypeptide (PP) antibodies diluted 1/2000 in PBS containing 1\% BSA (all antibodies from DAKO) for $30 \mathrm{~min}$. After washing with PBS for $20 \mathrm{~min}$, sections were incubated with second antibodies using biotinylated goat anti-guinea pig IgG diluted 1/2000 in PBS for insulin, and biotinylated goat anti-rabbit IgG for glucagon, somatostatin and PP (Vector Laboratories Inc.) for $30 \mathrm{~min}$. Positive reaction was visualized with an incubation in peroxidase substrate solution containing DAB (3,3'-diaminobenzidine) (Zymed Laboratories Inc., San Francisco, CA).

For detection of duct cell-specific cytokeratin, deparaffinized sections were pre-treated with PBS containing $0.25 \%$ trypsin (Sigma Chemical Co., St. Louis, MO) for $5 \mathrm{~min}$ at room temperature before blocking endogenous peroxidase with $3 \% \mathrm{H}_{2} \mathrm{O}_{2}$ solution for $10 \mathrm{~min}$. After washing in PBS, sections were incubated with $1.5 \%$ normal goat serum diluted in PBS for $20 \mathrm{~min}$. Sections were then incubated with rabbit anti-bovine epidermal cytokeratin (Nichirei Co., Ltd., Tokyo, Japan) for $30 \mathrm{~min}$. It is well known that there are several types of cytokeratin in both exocrine and endocrine cells. This antibody could detect only duct cells in the pancreas [16]. After washing the sections in PBS for $20 \mathrm{~min}$, the ABC method was applied as described above.

To identify the cell type producing BTC, we prepared several sets of mirror sections from each tissue block. In each set of mirror sections, immunostaining for BTC was performed in one section and for pancreatic hormones (insulin, glucagon, somatostatin and PP) or cytokeratin in another section.

Since BTC has been shown to bind to EGF receptor (erbB1) and erbB4, we tried to detect both receptors in normal pancreas and islet cell tumor tissues using $\mathrm{ABC}$ method described above using rabbit anti-erbB1 polyclonal antibody (Santa Cruz Biotechnology Inc., CA) and rabbit anti-erbB4 (C18) polyclonal antibody (Santa Cruz Biotechnology Inc.) diluted $1 / 200$ in PBS containing 1\% BSA.

All the sections were counterstained with methyl green or Mayer's hematoxylin, mounted with aqueous mounting medium (PermaFluor ${ }^{\circledR}$; Immunon, Pittsburgh, PA), and observed on light microscope PROVIS AX80 (Olympus, Tokyo, Japan). 


\section{Results}

\section{Immunohistochemical detection of BTC and cell types producing BTC in normal adult and fetal pancreas}

In normal pancreas, islet cells showed various degrees of immunoreactivity to BTC as shown in Figures 1 and 2, and the majority of islet cells showed faint or weak, but distinct immunostaining for BTC.
Among the islet cells with positive immunostaining for BTC, cells which appeared to be localized on the periphery of islet and along the intra-islet capillary network showed strong immunoreactivity to this protein. In exocrine pancreas, positive immunostaining for BTC was detected in many of the duct cells including intercalated duct and centroacinar cells (Fig. 1a and b), but no immunoreactivity to BTC was detected in acinar cells. Essentially the same staining result was obtained using two kinds of antibodies, pAb-MBT and pAb-CBT. Positive im-
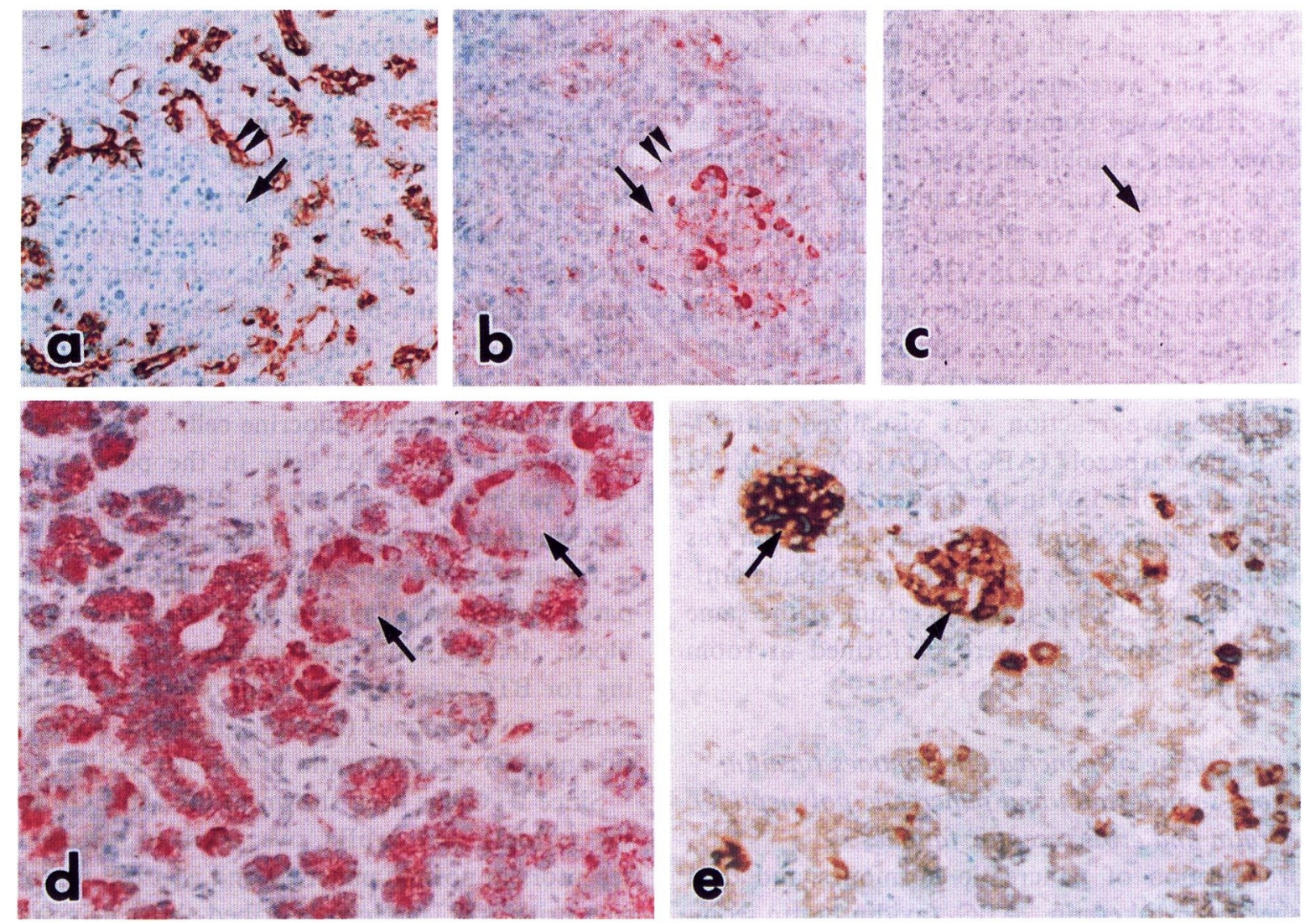

Fig. 1a-e. Immunostaining for duct cell-specific cytokeratin (DCK) and BTC in normal human pancreas, and for BTC and insulin in human fetal pancreas (about 4 months of gestation). Duct cells including intercalated and centroacinar cells were positive for DCK (brown color), but endocrine cells of islet (arrow) and acinar cells were virtually negative (a). In the islet (arrow in Fig. 1b) which corresponds to that in section a, some of the islet cells showed positive immunoreactivity to BTC (antibody: pAb-CBT) (red color). In the exocrine pancreas, faint but distinct immunostaining for BTC was observed in inter- and intra-lobular duct cells (double arrowheads) in addition to intercalated and centroacinar duct cells (b). From the staining pattern of DCK and BTC in two mirror sections, BTCpositive cells in exocrine pancreas were duct cells ( $a$ and $b$ ). In negative control, the immunoreactivity to BTC was completely abolished (c). In the fetal pancreas, strong immunoreactivity to BTC (pAb-MBT) was detected in primitive duct cells, while the cells of islet or islet-like structure showed only faint or negative immunostaining for this protein (d). In the replicate section, such cells of islet or islet-like structures were insulin-positive (brown color, arrows in Fig. 1e). a and e: ABC method, b, c and d: PAP method. Nuclear counterstaining: methyl green for a and e; Mayer's hematoxylin for b, $c$ and d. $(a, b$ and $c$ : original magnification $\times 160$; $d$ and e: original magnification $\times 220$ ) 

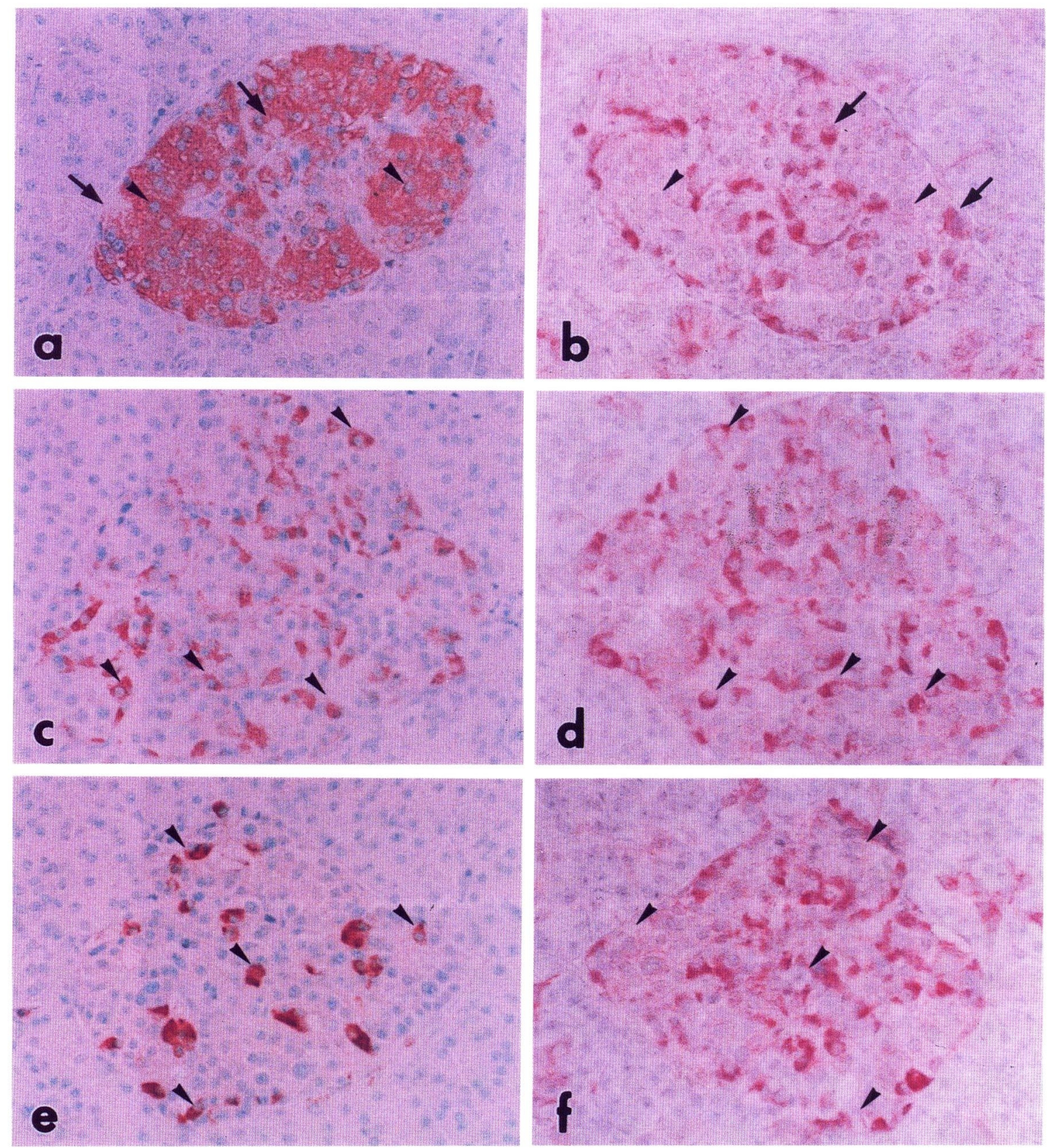

Fig. 2a-h. Cell type-specific localization of BTC in islet cells of normal human pancreas. In three sets of mirror sections (a and b, $c$ and d, and e and f), one section of each pair was immunostained for insulin and glucagon, respectively. All of the other sections in each pair were immunostained for BTC (antibody: pAb-MBT). (a and b) Islet cells positively stained for insulin (brown color) were almost negative for BTC, although some insulin-positive cells appeared to have faint or very weak immunoreactivity to this protein (arrowheads). Among insulin-negative cells (arrows in Fig. 2a), cells strongly positive for BTC could be detected. (Cells indicated by arrows and those indicated by arrowheads in Fig. 2a correspond to the cells indicated by arrows and those indicated by arrowheads in Fig. 2b, respectively.) (c and d) All glucagon-producing cells showed positive immunostaining for BTC. (Three glucagon-producing cells indicated by arrowheads in Fig. $2 \mathrm{c}$ are the same cells as those indicated by arrowheads in Fig. 2d.) (e and f) Somatostatin-producing cells scattered in the islet showed no immunostaining for BTC. (Three somatostatinproducing cells indicated by arrowheads in Fig. 2e are the same three non-BTC-producing cells indicated by arrowheads in Fig. 2f.) a, c and e: ABC method, b, d and f: PAP method. Nuclear counterstaining: methyl green for a, c and e; Mayer's hematoxylin for $b, d$ and $f$. (a-e: original magnification $\times 300$ ) 

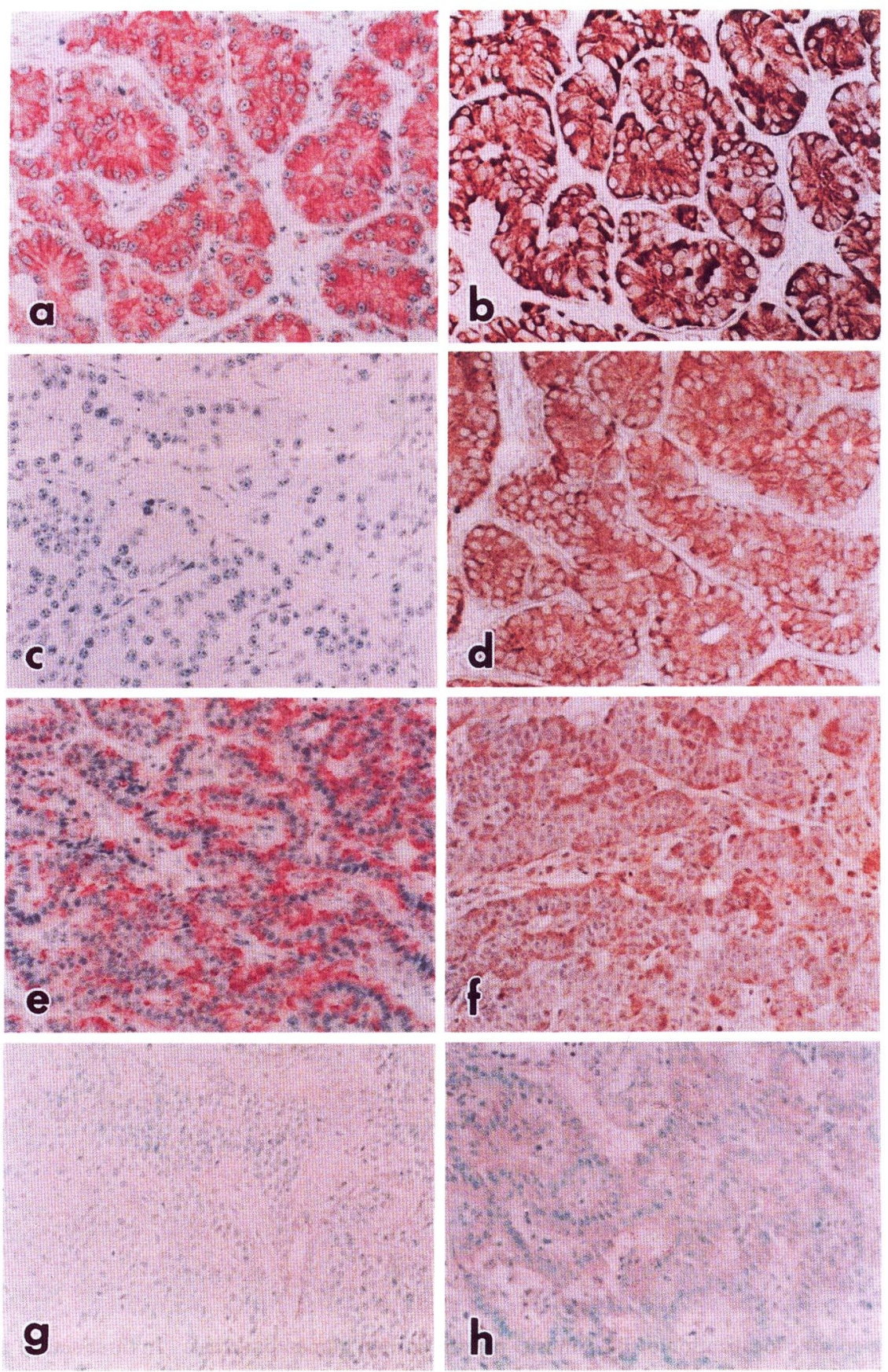

Fig. 3a-h. Immunohistochemical localization of BTC, insulin and erbB1 (EGF receptor) in insulinoma tissues, and BTC, and glucagon, insulin and erbB1 in glucagonoma tissue of MEN type I. In this insulinoma tissue, tumor cells tended to form a luminal structure, and positive staining for BTC (antibody: pAb-MBT) was detected in almost all insulinoma cells (red color). These BTC-producing tumor cells were also positive for insulin ( $a$ and $b$ ). In negative control for BTC staining, immunoreactivity to BTC was completely abolished (c). ErbB1 was also expressed in these insulinoma cells (d). In glucagonoma tissue, almost all tumor cells were positive for BTC (pAb-MBT) (red color) (e). These cells showed various degrees of immunoreactivity to glucagon (brown color) (f). In this tumor, the immunoreactivity to insulin was virtually absent (g). Expression of erbB1 on these cells appeared to be at a very low or undetectable level compared to that of insulinoma cells (h). a, c and e: PAP method. b, d, f, g and h: ABC method. Nuclear counterstaining: Mayer's hematoxylin for a, $c$, e and f; methyl green for $\mathrm{g}$ and $\mathrm{h}$ (not done in $\mathrm{b}$ and d). (a-d: original magnification $\times 280$; e-h: original magnification $\times 220$ ) 
munostaining was completely abolished when the primary antibody was preabsorbed with antigen peptides or recombinant human BTC (Fig. 1c).

In fetal pancreas at about 16 weeks of gestation, parenchymal tissue consisted of ductular and isletlike structures, and fibroblast-like cells scattered in the connective tissue space. Ductular cells showed strongly positive immunoreactivity to BTC. In cells of islet-like structure, some populations of the cells localized on the periphery also showed strong positivity for BTC, but the cells mainly localized in the center showed almost no immunostaining (Fig. 1d). At this stage of gestation, mature islet structure was rarely recognized, and islet-like structures were usually associated with duct or ductular epithelium. As shown in Figure 1e, cells localized in the center of islet-like structure showed strong immunostaining for insulin, suggesting that they were mature $\beta$ cells. In a set of mirror sections (Fig. 1d and e), it was demonstrated that cells with almost no immunostaining for BTC were those which were strongly positive for insulin. Glucagon-positive cells scattering in both ductular and islet-like structures were also observed, but the number was very small compared to that of insulin-positive cells at this stage of gestation (data not shown).

To determine the cell type producing BTC in islets, we compared the localization of BTC-positive or -negative islet cells with that of islet cells immuno- stained for four kinds of pancreatic hormones, i.e., insulin, glucagon, somatostatin and PP using several pairs of mirror image sections. In a set of insulin-BTC staining pair, insulin-producing cells appeared to be negative for BTC, although some of the insulin-producing cells showed faint or very weak immunostaining for this protein (Fig. 2a and b, arrowheads). In contrast, in a set of glucagon-BTC immunostaining pairs, all of the glucagon-producing cells mainly localized on the periphery of islet and along the intra-islet capillary network showed positive immunostaining for BTC (Fig. 2c and d). Among the BTC-negative cells, there also appeared to exist insulin-negative or glucagon-negative cells. As shown in a set of somatostatin-BTC staining pairs (Fig. 2e and $\mathrm{f}$ ), somatostatin-producing cells had no immunoreactivity to BTC. PP-producing cells also showed no immunoreactivity to this protein (data not shown). Thus, glucagon-producing $\alpha$ cells and probably some populations of insulin-producing $\beta$ cells produced BTC protein in normal islet cells.

\section{Immunohistochemical localization of BTC in islet cell tumor tissues}

In islet cell tumors, insulinoma cells of all patients showed positive immunoreactivity to BTC (Fig. 3a and b). EGF receptor was also detected in insulinoma cells of all cases examined (Fig. 3d). Since BTC
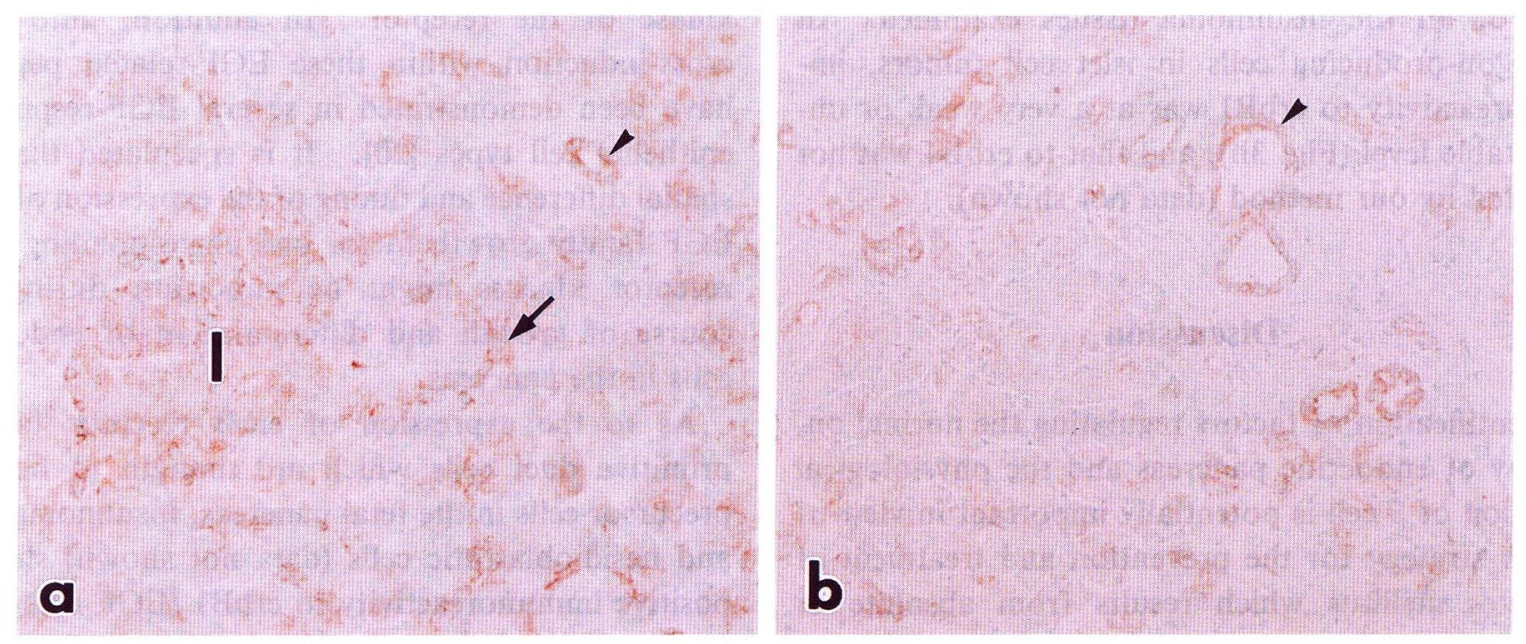

Fig. 4a, b. Detection of erbB1 (EGF receptor) and erbB4 in normal human pancreas. In sections from normal pancreas tissue, erbB1 was expressed in islet cells (I: islet), and duct epithelium (arrowhead). Duct cells of intralobular small ducts (arrow) also expressed erbB1, while acinar cells showed only faint immunostaining for the receptor (a). Positive immunostaining for erbB4 was detected mainly in duct cells (arrowhead) (b). a and b: ABC method. Nuclearcounterstaining: methyl green for $a$ and $b$. ( $a$ and $b$ : original magnification $\times 200$ ) 
was more abundant in glucagon-producing cells than in insulin-producing cells in normal pancreas, we examined whether glucagonoma cells produced this protein or not. Glucagon-producing cells of islet cell tumor (glucagonoma) from all patients also showed strong immunoreactivity to BTC (Fig. $3 \mathrm{e}$ and f). No insulin-positive cells were detected in this tissue (Fig. 3g). Thus, in all human islet cell tumors examined, both insulinoma and glucagonoma cells produced BTC protein.

\section{Detection of erbB1 (EGF receptor) and erbB4 in normal human pancreas and islet cell tumor tissues}

Since we confirmed that BTC is produced in normal human pancreas, we next determined the cell type(s) expressing erbB1 and/or erbB4 receptors in normal human pancreas. Positive immunostaining for erbB1 was detected in almost all islet cells and duct cells. ErbB 1 appeared to be also expressed more or less in acinar cells by our method (Fig. 4a). In contrast, positive immunostaining for erbB4 was detected only in duct cells including intralobular small duct cells in all the pancreatic tissues examined (Fig. 4b). Thus, the different expression patterns of erbB1 and erbB4 were observed in the normal human pancreas.

In endocrine cell tumor tissues, positive immunostaining for erbB1 (Fig. 3d) but not for erbB4 (data not shown) was detected in insulin-producing cells of all the insulinoma tissues examined. In glucagon-producing cells in islet cell tumors, immunoreactivity to erbB1 was at a very weak or undetectable level (Fig. 3h), and that to erbB4 was not detected by our method (data not shown).

\section{Discussion}

Identification of factors regulating the normal ontogeny of endocrine pancreas and the physiological function of $\beta$ cell is potentially important in view of a new strategy for the prevention and treatment of diabetes mellitus which results from absolute or relative lack of insulin-producing $\beta$ cell mass or its function. Islet cell growth and/or differentiation factors are also of importance for the graft viability and the maintenance of islet or pancreas transplants which could provide another type of treatment for the disease.

The results of this study have demonstrated that BTC is localized in distinct populations of cell types in normal islets, islet precursor cells of the fetal pancreas and islet cell tumors. Since immunohistochemical staining patterns of BTC using two kinds of antibodies, pAb-MBT and pAb-CBT, were almost the same, it is considered that the cells with positive immunostaining for BTC actually produced this growth factor. We previously demonstrated that BTC mRNA was predominantly expressed in normal human pancreas tissue [17]. These evidence suggest that BTC play an important role(s) in the ontogeny of the endocrine pancreas as well as in islet cell tumorigenesis.

Among growth factors of the EGF family, TGF- $\alpha$, HB-EGF (heparin-binding EGF-like growth factor), and perhaps EGF have been shown to be important for the growth and differentiation of endocrine and exocrine cells of the pancreas. TGF- $\alpha$, the carboxy terminal domain of which has $50 \%$ homology with the corresponding 50 -amino acid sequence of BTC, is expressed in human fetal pancreas and in many pancreatic cancer cell lines [7, 18]. HB-EGF is also expressed in the rat pancreas, and may function as one of the mediators of IPF1/PDX-1 (insulin promoter factor 1/pancreatic duodenal homeobox gene-1) [19]. These growth factors of the EGF family are known to bind to erbB receptor kinases to induce various biological effects by autophosphorylation of tyrosine kinase of the receptor. In addition, auto- and cross-induction within these EGF-related peptides have been demonstrated in several EGF-responsive epithelial cell types [20]. It is speculated that the spatial difference and timing of the expression of each EGF family growth factor and corresponding erbB receptor kinases might be important during the course of growth and differentiation of endocrine cells in the pancreas.

As to the expression of erbB receptor family, primitive duct cells which are thought to be islet precursor cells in the fetal pancreas, insulinoma cells and nesidioblastotic cells (data not shown) showed positive immunoreactivity to erbB1 (EGF receptor). In this study, we have demonstrated the different expression patterns of erbB1 and erbB4. In the adult pancreas, islet cells expressed erbB1 but not erbB4, while duct cells expressed both erbB1 and erbB4. Neither erbB2 nor erbB3 was immunohistochemically 
detected in acinar, duct and endocrine cells (data not shown), although Huotari et al. reported that erbB2 mRNA was expressed in rat pancreas [15]. It is speculated that erbB1 and/or erbB4 mediate the biological effect of BTC which might exert biological effects different from other growth factors of EGF family depending on the expression pattern of these two erbB receptor tyrosine kinases in the pancreas.

In normal islets, BTC was detected in glucagonproducing $\alpha$ cells and probably in some populations of insulin-producing $\beta$ cells, although the detectable level in $\beta$ cells was very low in our method. BTC produced in these cells may well act on themselves or neighboring cells in autocrine, paracrine and/or juxtacrine fashion, and may maintain physiological function of islet cells. Since an islet-acinar blood flow axis (islet/acinar portal system) exists, it is also possible that BTC secreted by islet cells contributes to the growth and functional maintenance of exocrine cells such as acinar and duct cells to which EGF has been reported to bind [21, 22].

The BTC-specific role in the development and regeneration of endocrine pancreas, and in the normal islet remains to be elucidated. So far, it has been demonstrated that BTC was mitogenic for vascular smooth muscle cells and retinal pigment epithelial cells, but not so for human fetal lung fibroblasts, bovine aortic and capillary endothelial cells [1]. In pancreatic endocrine cells, BTC appears to act as a mitogen in INS-1 cells which express erbB1, but not erbB4 [15]. Recently, Mashima et al. demonstrated that BTC could convert amylase-secreting AR42J cells derived from chemically-induced rat pancreatic tumor into insulin-producing cells dose-dependently in the presence of activin A [13], and that BTCspecific binding protein with a molecular weight of
$190 \mathrm{Kda}$ was reported to be involved in this process [23]. Interestingly, this unique effect of BTC was not observed with other growth factors of EGF family such as EGF and TGF- $\alpha$. Furthermore, activin A which belongs to TGF- $\beta$ (transforming growth factor- $\beta$ ) superfamily, was expressed in glucagon-secreting $\alpha$ cells in rat islets $[24,25]$. These lines of evidence suggest that BTC could be involved in the process of differentiation of $\beta$ cells in paracrine, autocrine, and/or juxtacrine manner.

In conclusion, this study has demonstrated for the first time the localization of BTC protein, a new member of the EGF family, in normal human pancreas and islet cell tumors. Variable amounts of BTC were expressed in $\alpha$ cells and duct cells, and probably in $\beta$ cells in normal adult pancreas, and, to a greater extent, in fetal pancreas and islet tumor cells. The results of this study together with other reports discussed above suggest that BTC may be involved in the process of growth and/or differentiation of pancreatic endocrine cells.

\section{Acknowledgments}

We thank Professor M. Monden, Associate Professors H. Shiozaki and M. Sakon of the Department of Surgery and Clinical Oncology, Graduate School of Medicine, Osaka University for providing pancreas and insulinoma tissues. The present study was supported in part by Scientific Research Funds (No. 9671056, 11671087, 11770641) from the Ministry of Education, Science and Culture of Japan, the Yamanouchi Foundation for Research on Metabolic Disorders, and the Inamori Foundation.

\section{References}

1. Shing Y, Christofori G, Hanahan D, Ono Y, Sasada R, Igarashi K, Folkman J (1993) Betacellulin: a mitogen from pancreatic beta cell tumors. Science 259: 1604-1607.

2. Sasada R, Ono Y, Taniyama Y, Shing Y, Folkman J, Igarashi K (1993) Cloning and expression of cDNA encoding human betacellulin, a new member of the EGF family. Biochem Biophys Res Commun 190: 1173-1179.

3. Watanabe $T$, Shintani A, Nakata $M$, Shing $Y$,
Folkman J, Igarashi K, Sasada R (1994) Recombinant human betacellulin. Molecular structure, biological activities, and receptor interaction. J Biol Chem 269: 9966-9973.

4. Riese II DJ, Bermingham Y, van Raaij TM, Buckley S, Plowman GD, Stern DF (1996) Betacellulin activates the epidermal growth factor and erbB-4, and induces cellular response patterns distinct from those stimulated by epidermal growth factor or neuregulin$\beta$. Oncogene 12: 345-353. 
5. Like AA, Orci L (1972) Embryogenesis of the human pancreatic islets. Diabetes 21: 511-534.

6. Pictet RL, Clark WR, Williams RH, Rutter WJ (1972) An ultrastructural analysis of the developing embryonic pancreas. Dev Biol 29: 436-467.

7. Miettinen PJ, Heikinheimo K (1992) Transforming growth factor-alpha (TGF- $\alpha$ ) and insulin gene expression in human fetal pancreas. Development 114: 833-840.

8. Damjanov I, Mildner B, Knowles BB (1986) Immunohistochemical localization of the epidermal growth factor receptor in normal human tissues. $L a b$ Invest 55: 588-592.

9. Sandgren EP, Luetekke NC, Palmiter RD, Brinster RL, Lee DC (1990) Overexpression of TGF $\alpha$ in transgenic mice: induction of epithelial hyperplasia, pancreatic hyperplasia, and carcinoma of the breast. Cell 61: 1121-1135.

10. Jhappan C, Stahle C, Harkins RN, Fausto N, Smith GH, Merlino GT (1990) TGF $\alpha$ overexpression in transgenic mice induces liver neoplasia and abnormal development of the mammary gland and pancreas. Cell 61: 1137-1146.

11. Matsui YS, Halter A, Holt JT, Hogan BML, Coffey RJ (1990) Development of mammary hyperplasia in MMTV-TGF $\alpha$ transgenic mice. Cell 61: 1147-1155

12. Bockman DE, Merlino G (1992) Cytological changes in the pancreas of transgenic mice overexpressing transforming growth factor $\alpha$. Gastroenterology 103: 1883-1892.

13. Wang TC, Bonner-Weir S, Oates PS, Chulak M, Simon B, Merlino GT, Schmidt EV, Brand SJ (1993) Pancreatic gastrin stimulates islet differentiation of transforming growth factor $\alpha$-induced ductular precursor cells. J Clin Invest 92: 1349-1356.

14. Mashima $H$, Ohnishi $H$, Wakabayashi $K$, Mine $T$, Miyagawa J, Hanafusa $T$, Seno $M$, Yamada $H$, Kojima I (1996) Betacellulin and activin A coordinately convert amylase-secreting pancreas AR42J cells into insulin-secreting cells. J Clin Invest 97: 1647-1654.

15. Huotari M-A, Palgi J, Otonkosky T (1998) Growth factor-mediated proliferation and differentiation of insulin-producing INS-1 and RINm5F cells: identification of Betacellulin as a novel $\beta$-cell mitogen. Endocrinology 139: 1494-1499.

16. Waguri M, Yamamoto $\mathrm{K}$, Miyagawa J, Tochino $\mathrm{Y}$,
Yamamori K, Kajimoto Y, Nakajima H, Watada H, Yoshiuchi I, Itoh N, Imagawa A, Namba M, Kuwajima M, Yamasaki Y, Hanafusa T, Matsuzawa Y (1997) Demonstration of two different processes of $\beta$-cell regeneration in a new diabetic mouse model induced by selective perfusion of alloxan. Diabetes 46: 1281-1290.

17. Seno $\mathbf{M}$, Tada $\mathbf{H}$, Kosaka $\mathbf{M}$, Sasada $\mathbf{R}$, Igarashi $\mathrm{K}$, Shing Y, Folkman J, Ueda M, Yamada H (1996) Human betacellulin, a member of EGF family dominantly expressed in pancreas and small intestine, is fully active in a monomeric form. Growth Fact 13: 181-191.

18. Smith JJ, Deryunck R, Kork M (1987) Production of transforming growth factor $\alpha$ in human pancreatic cancer cells: Evidence for a superagonist autocrine cycle. Proc Natl Acad Sci USA 84: 7567-7570.

19. Kaneto H, Miyagawa J, Kajimoto Y, Yamamoto K, Watada H, Umayahara Y, Hanafusa T, Matsuzawa Y, Yamasaki Y, Higashiyama S, Taniguchi N (1997) Expression of heparin-binding epidermal growth factor like growth factor during pancreatic development. J Biol Chem 46: 29137-29143.

20. Bernard JA, Graves-Deal R, Pitterkow MR, DuBois R, Cook P, Ramsey GW, Bishop PR, Damstrup L, Coffey RJ (1994) Auto- and cross-induction within the mammalian epidermal growth factor-related peptide family. J Biol Chem 269: 22817-22822.

21. Korc M, Matrisian LM, Plank SR, Magun BE (1983) Binding of epidermal growth factor in rat pancreatic acini. Biochem Biophys Res Commun 111: 10661073.

22. Brockenbrough JS, Weir GC, Korc M (1988) Alteration in EGF binding to scini during pancreatic regeneration in the rat. Int $J$ Pancreatol 3: 413-424.

23. Ishiyama $\mathbf{N}$, Kanzaki $\mathbf{M}$, Seno $\mathbf{M}$, Yamada $\mathrm{H}$, Kobayashi I, Kojima I (1998) Studies on the betacellulin receptor in pancreatic AR42J cells. Diabetologia 41: 623-628.

24. Yasuda $H$, Inoue $K$, Shibata $H$, Takeuchi $T$, Eto $Y$, Hasegawa Y, Sekine N, Totsuka Y, Mine T, Ogata E, Kojima I (1993) Existence of activin A in A- and Dcells of rat pancreatic islet. Endocrinology 133: 624630.

25. Furukawa M, Eto Y, Kojima I (1994) Expression of immunoreactive activin $\mathrm{A}$ in fetal rat pancreas. Endocrine J 42: 63-68. 